\title{
Risky Sexual Behaviour, Sexually Transmitted Infections, HIV/AIDS and Health Promotion among Students in the University of Douala
}

\author{
PR. NJIKAM née SAVAGE , O. M. \\ Head of Department \\ Sociology and Communication \\ University of Douala \\ Douala, Cameroon
}

\begin{abstract}
There are about 9,335 students in the University of Douala, 6,686 males and 3,832 females with a mean age of 20 years. Knowledge of the transmission of AIDS is high as indicated by $95 \%$ of the students, $80 \%$ were also able to identify preventive strategies. However, there is a failure to translate knowledge into protective action and behaviour. Between 1998 and 2001, there has been a nearly three-fold increase in cases of STIs from 137 to 360. Tuberculosis, which is strongly linked to HIV/AIDS in Douala, has also increased from 7 cases to 38. HIV/AIDS prevalence among students is estimated between 3\%-5\%. Both male and female students constitute a high-risk group because of multiple partners due to the adoption of several supposedly emotional/financial safe strategies. These include sponsors ${ }^{1}$ or male friends who pay rents, furnish rooms etc, in addition to campus girl friends/boy friends 'safety belts' and other short-term relationships. Condom usage is irregular. The University of Douala as part of its health promotion-prevention strategy has intensified its information, education and communication programme on HIV/AIDS with the support of governmental, non-governmental organisations and students clubs on campus and Peer educators have increased their sensitization activities. Preventive strategies include valorising positive cultural norms, empowering and encouraging students to practice sexual abstinence and fidelity. There is a need to incorporate students more in the design of appropriate and acceptable intervention strategies towards the prevention, health enhancement, treatment and management strategies of HIV/AIDS in the university arena.
\end{abstract}

\section{Introduction}

Students of the University of Douala have the advantage of living in the nation's economic capital, which in itself confers them access to some of the best health facilities. On the other hand, the fast pace of life in Douala may increase their potential health risks, specifically with respect to fleeting relationships, multiple partners and subsequent exposure to sexually transmitted infections (STIs) and HIV/AIDS. The student population is about 9,335 with 6,686 males and 3,832 females and a mean age of about 20 years of age. As it is the case with other institutions of higher learning, there is a preponderance of males over female students, although the gender gap has reduced considerably over the last decade alongside a general increase in students' enrolment. The University of Douala, like all other state universities, has a Health Centre that provides medical services to students and to a lesser extent staff. In addition, a number of youth clubs on Campus 
are geared towards a variety of health maintenance and disease prevention programmes, namely through information, education and communication (I.E.C) strategies e.g. 'Mutuelle de Solidarité des Etudiants du Cameroun (MUSEC), Red Cross, Cameroon National Association for Family Welfare (CAMNAFAW), Programme de Marketing Social au Cameroun (PMSC) etc. This article examines the sexual behaviour of female and male students of the University of Douala within the context of sexually transmitted infections (STIs), perceptions and attitudes to HIV/AIDS, including persons living with HIV/AIDS (PLWHAS), perceptions and use of condoms, gender differences in perceived risk of exposure to HIV/AIDS and female coping/management strategies to reduce risks. Lastly, it identifies potential strategies to promote, enhance and effectively manage the reproductive health of young women and men within the university campus.

\section{Methods}

Qualitative studies were conducted among students from March to May 2002. This started off with informal semi-structured discussions with two groups of 15 students each. These informal discussions involved both sexes and formed the basis for the development of a focus group and an in-depth interview guide. Two focus group discussions (FGDs) each were subsequently conducted among 10 female and 10 male students. In addition, 40 in-depth interviews each were also carried out among students in the four Faculties (Sciences, Arts and Social Sciences, Law and Political Jurisprudence, and Economics and Management Sciences) and three Professional Institutions (University Institute of Technology, Higher Institute of Economics and Commerce and the Advanced Teachers Technical Training Institute), which make up the University of Douala. Thus, in all, there were 320 participants: 160 females and 160 males. Two graduate students from the Department of Sociology-Communication, with some experience as field assistants, were trained to conduct the in-depth interviews and record the FGDS.

Study participants were recruited on campus by peers of the same sex in between lectures, at the end of lectures and during weekends. The FGDs, like the informal discussions, dwelt on perceptions on condom, students' sexual behaviour and HIV/AIDS. The FGDs were conducted during the term, in empty lecture rooms. Discussions were very frank and open with the active participation of both sexes. The fact that the facilitator was familiar with some of the students did not result in any apparent shyness but rather reduced reticence among them. A facilitator, who allowed the discussions to flow among participants until the next theme, which invariably emerged during the discussion, was then introduced, led the discussions. In-depth interviews took place in private places such as students' rooms, open and recreational spaces such as sports field and snack spots. In-depth interviews also included knowledge, mode of infection and prevention of HIV/AIDS, experience and prevention of STIs, perceptions of HIV/AIDS as well as persons living with HIV/AIDS (PLWHAS), sexual 
behaviour and use of birth control methods, perceived risk of HIV/AIDS infection by females and their coping/adopted risk reduction strategies. Both the FGD and in-depth interview guides had been pre-tested among students in three institutions of private higher education in Douala and were subsequently modified for clarity before final administration.

\section{Data Analysis}

Debriefing sessions were held immediately after each FGD with the research team, the emerging issues discussed informally with particular focus on unexpected issues. Subsequently, the tapes were transcribed and the manuscripts typed and then coded on the basis of the following themes: perceptions of HIV/AIDS and infected persons, condom usage and perception, other risk reduction strategies lastly, gender and perception of risk of HIV/AIDS infection. Subsequent meetings were then held to review and discuss the emerging results of the analysis. At the end of these sessions, data from the FGDS and in-depth interviews was analysed using content analysis. Emerging themes as well as the frequencies with which the themes re-occurred among participants were then noted. Finally, the results of both the FGDS and in-depth interviews were merged and then re-grouped by themes as presented below. Generalisations cannot be made from the results due to the non-representative nature and size of the sample. Nonetheless, they provide valuable insights as regards some aspects of sexual behaviour among university students which could be further explored in order to better understand issues of sexuality and risk reduction for sexually transmitted infections and HIV/AIDS.

\section{Socio-Demographic Characteristics}

The age of female students ranged from 18-32 years, with a mean of 22 years. Males were slightly older with an age range of 20-39 years and a mean of 27 years. The majority of students were single, $72.5 \%$ (116) of females compared to $88.12 \%$ (141) of males. About $28 \%$ of the females (or 44 ) admitted being involved in free unions or concubinage, while none of their male counterparts made such claims. The majority of the students (females as well as males) were Christians (86.25\% or 276); Moslems comprised 9.06\% (29), while $4.69 \%$ (15) apiece belonged to Pentecostal churches or had no religious affiliation. Third year students constituted the largest category (60\% or 192), followed by first year students $30 \%$ (96). Despite this apparent imbalance in the representativeness of students, it was not perceived as a severe drawback. Firstly, third year students, having spent more time on campus, were likely to be more at ease with the social environment and as such more accommodating to questions on issues pertaining to their sexuality. Secondly, they were therefore more likely to give frank responses. 


\section{The context of students' sexual behaviour and HIV/AIDS}

The attitudes of Cameroonian students towards HIV/AIDS in have witnessed considerable changes. In 1993, an exploratory study conducted among students of the University of Douala revealed that attitudes to HIV/AIDS ranged from being regarded as a fiction thereby resulting in incredible disbelief of its existence, to grudging acceptance of its existence in European countries but certainly not in Africa, much less Cameroon. Consequently, the majority of students regarded HIV/AIDS as a mere fiction. It was perceived as a smokescreen and a clever guise to discourage sexual activity and promiscuity among sexually active groups, including youths (Njikam Savage, 1993). The results of a subsequent study (Njikam Savage, 1998) supported the continued scepticism and disbelief in the existence of AIDS in Cameroon, and in addition revealed that males as well as females were in favour of 'full contact'(students' metaphor for unprotected sex). Rather, they believed in a 'safe strategy' of having multiple sexual partners, since they could never be sure of the faithfulness of their campus girlfriends or boyfriends. This was perceived as some sort of social insurance in case a boy/girl friend abandoned one.

\section{STIs, HIV/AIDS Prevalence among Students in the University of Douala}

There has been no official case of self-declared AIDS or HIV infection among University of Douala students. However, there has been a large increase in the number of students who seek information on behalf of their friends or relatives who are HIV positive or are living with AIDS. Some of these students have paid incessant visits to the Health Centre and some of the health-oriented clubs on campus supposedly for their friends or relatives. Studies in health and social sciences recognise that individuals are often more comfortable in disguising their own needs with that of others especially in cases where they are afraid of social stigma, labelling and the loss of their social identity in replacement by the master status trait. Accordingly, all previous attributes associated with the individual are forgotten and only the new images of the person as conjured by the disease takes over the identity of the person. In such a context, denial, refusal and mindless as well as wilful propagation of the virus and disease may result. HIV/AIDS in the University arena is still without a face. The fear of withdrawal, rejection and isolation is still very strong among students as in the general population.

Consequently, only a rough estimate of HIV / AIDS prevalence can be gleaned from the student population. Nonetheless, the frequent blood donation drives initiated by the Red Cross over the past five years provide some indications on its growing prevalence. The sero-prevalence from blood donation ranges from 1\%-3\% while the level among students has been estimated at between 3\%-5\% (MINESUP, Kribi Project, 2001). However, the quality of data from such exercises poses some problems. Firstly, the 
students who volunteer for blood donation are not representative of the general student population and to that extent the results cannot be generalised. Secondly, the number of volunteers is small compared to the total student population. Lastly, as the blood analysis is undertaken outside the campus the risks of false negatives or positives cannot be discounted in the results. Thus, until an appropriately designed behaviouralepidemiological study is undertaken among university students, only rough estimates of sero-prevalence and other crucial information with varying margins of error are available. Available statistics from the University Health Centre of three state universities indicate nearly a three-fold increase from 137 cases of STIs in 1998/1999 to 360 cases in the 2000/2001 academic year. Also, a survey conducted in collaboration with the National AIDS Control Committee NACC in 2001 on persons living with AIDS in five urban hospitals in Yaounde revealed that out of 2,400 cases, nearly 10\% (256), comprised students. The University campus is situated near two identified zones of high HIV/AIDS transmission: Ndokoti and Omnisport/Bepanda (Meeting of Experts on HIV/AIDS Prevention, 2003). It is, therefore, evident that students from the University of Douala are unlikely to remain unaffected.

Furthermore, the prevalence of tuberculosis during this period has more than quadrupled from 7 cases in 1998/1999 to 38 cases in 2000/2001. This is significant because tuberculosis is currently strongly related to HIV/AIDS as an opportunistic infection (Jaramillo, 1999). Indeed, a study conducted by Kuaban and Bercion (1996) in Yaounde acknowledged HIV as one of the most important factors that promoted the development of tuberculosis. They also identified tuberculosis as the most common complication among HIV cases especially among young adults. Consequently, individuals requesting to be vaccinated against tuberculosis are now required by the Ministry of Public Health to undergo preliminary screening (Mono test) to ascertain the presence or absence of antibodies before vaccination. This is in order to avoid the further worsening of an already compromised immune system.

Clients without antibodies are strongly advised to undertake an AIDS test and or chest X-ray to confirm their health status. About three-quarters of persons with active pulmonary tuberculosis (PWT) as well as related deaths in developing countries are within the 15-59 age range, almost identical with those at risk of HIV/AIDS (Khan et al., 2000). Although government has considerably reduced the cost of therapy for tuberculosis to an equivalent of $\$ 3.25$, the disease and treatment is stigmatising and its timely diagnosis unaffordable to the majority of those who need it. Consequently, there is considerable waiting time before the first onset of signs and appropriate treatment.

\section{Condom: Perceptions and Usage}

Students identified three categories of sexual partners/relationship: meilleure amie or their principal partner, secondary partner and occasional partner. 
The first category represented a partner with whom they perceived they had a regular or stable relationship which was expected to lead to engagement and subsequent marriage. The secondary relationship which may well be of the same duration as the first category but was not perceived as having the same importance especially in terms of emotional investment and future expectations. Secondary relationships were regarded as stand-bys. The last category comprised one-night stands or spontaneous partners of no future consequence. The use of condoms varied among this category of partners.

Among those in primary relationships, about one half of students, $52.5 \%$ (168) said they used condoms with their partners to avoid STIs and unwanted pregnancies. However, $23.43 \%$ (75) stated they did not use condoms because they had total confidence in their partners. About a similar proportion $24.1 \%$ (77) reported irregular condom usage. For those who admitted having secondary and occasional relations, $40 \%$ of them used condoms while $4 \%$ and $12 \%$ respectively said they could not be bothered to do so. Third year students were more likely to use condoms than first years, $48 \%$ versus $12 \%$.

Female students appeared to practise mixed methods in their efforts to avoid pregnancy. Condoms were often used alongside abstinence. The type of methods used appeared to be related to the type of relationship one was involved in. As regards the different categories of relationships, those involved in primary relationships were the most likely to practice abstinence with their partners as compared with those in secondary or occasional relationships: $60 \%$ versus $24 \%$ and $20 \%$. The use of abstinence tended to be most common among students between 25 and 29 years of age $(40 \%)$ as compared to older ones who were 30 years and above $(8 \%)$ and those under 24 years $(16 \%)$.

Although condoms were perceived generally as an important means of preventing STIs especially HIV/AIDS, male students especially raised several negative issues concerning it. Firstly, it discouraged young people from knowing and mastering how their bodies functioned (physiology) because of the tendency to rely absolutely on condom usage. Thus, they claimed many students were ignorant of basic issues, such as fertile and infertile periods, ovulation etc. Secondly, they felt the propaganda to use condoms was driven by a huge commercial profit-making incentive and not so much by a concern or strategy to fight against HIV/AIDS as was often claimed. This, they insisted, was the reason for widespread adverts on condom usage all over the place, most of which carried no reference to HIV/AIDS. HIV/AIDS was simply used as an excuse to escalate the sales of condoms. According to these students, a cure of HIV/AIDS would therefore have a devastating effect on condom sales and may well be the reason for the foot-dragging in the funding of scientific research towards having a vaccine or a cure. Thirdly, the widespread use of condoms encouraged promiscuity and infidelity as partners were lulled by the promise of being protected against unwanted pregnancy (which would otherwise expose 
them as being sexually active or cheats, thus giving them away) and HIV/AIDS. Consequently, about 50\% (160) male and female students perceived condoms negatively, as being a bad thing. A minority of females (8.75\% or 28 ) felt disgusted and repulsed by condoms, which they did not perceive as being protective at all. This was because they believed that the condom could not withstand prolonged sex (as it could tear or burst), and in any case even with condom usage one was still exposed to the risk of $\mathrm{HIV} / \mathrm{AIDS}$ contamination in one way or the other.

Nonetheless, $72.25 \%$ (116) of girls said they used condoms to avoid being contaminated by HIV/AIDS, while $27.75 \%$ practised abstinence. Nearly ass the students (females and males) believed that the best way of avoiding HIV/AIDS was through the practice of fidelity and abstinence between partners. In reality, it was difficult to be faithful as a 22-year old female student explained, 'each person needs to have some assurance to fall back on, either within the context of academics or love life. Thus, female students had multiply partners to maximise their options.'

Therefore, to avoid being left in the lurch, it was prudent while having a (primary) regular boyfriend/girlfriend to still keep one on the side (secondary relationship) in case one was jilted (Njikam Savage, 1998). Also, one-night stands were not uncommon, and as some students admitted, in the spontaneity of such a context, condom usage was the furthest from their minds. In addition to their campus boyfriends, female students had 'sponsors', men-friend who among other things paid their rents, furnished their rooms (on or off campus) with modern electronic appliances e.g. televisions, stereo sets, gas cookers etc, bought them clothes and gave them feeding allowances. To these sponsors, the girls could not impose condom usage lest they in annoyance left and withdrew their financial support. On the other hand, condom usage was imposed on campus boyfriends at the onset of a relationship and was subsequently discarded as the relationship developed.

Campus boyfriends, in turn, benefited from these relationships through receiving small sums of money from their girlfriends, which helped towards the payment of photocopies for lectures, etc. The majority of the male students acknowledged and accepted the fact that they could not marry their classmates: they had neither employment nor savings to set up a home or support a wife. As a male student aged 25 years explained, 'one was pragmatic about these things (relations) and accepted the situation as such. Things only became problematic when one allowed ones heart to rule ones head.'

\section{Perceptions of HIV/AIDS and Risk of Infection}

There was unanimity in the perception of HIV/ AIDS as being real. Students felt it was a grave illness that was sexually transmitted and which resulted in death. Nonetheless, HIV/ AIDS was also easy to avoid according to both females and males. For 60\% (192) of them, HIV/AIDS resulted in a 
devastating illness that was prolonged, agonising and difficult to manage. There were two main perceptions of AIDS. Firstly, about $68 \%$ of the students perceived AIDS as a deadly and devastating illness. For this category, AIDS reduced its victims to living from day to day thereby preventing the realisation of all their plans and dreams. It involved prolonged suffering which inevitably resulted in death. Secondly, AIDS was perceived as a shameful disease by $32.19 \%$ (103), the ultimate result of sexual promiscuity and infidelity. This category of students was particularly worried about the re-action of others namely: neighbours, friends and society.

The majority of students $(78.75 \%$ or 252$)$ said they knew at least one person living with HIV/AIDS (PLWHAS). The totality of students claimed that HIV/AIDS had affected their sexual behaviour. About three-quarters of students $(72.5 \%$ or 232$)$ acknowledged they ran the risk of being infected by HIV / AIDS. Of this $74.14 \%$ (172), said they had a moderate risk while $12.93 \%$ (30) acknowledged having a low risk. About $6.5 \%$ apiece said they had very low and high risk of exposure to having HIV/AIDS. Among the 27.5\% (88) who claimed they had no risk of having HIV/AIDS, one-quarter felt that those whose were infected with the virus had no reason to live.

\section{Protective Strategies Adopted by Female Students to Avoid HIV/AIDS}

Three-quarters of females (75\% or 120) in the FGDs and in-depth interviews admitted having more than one male partner. However, several of them claimed they had sexual relations only with their principal boyfriends, limiting their interactions with the others to just going out and flirting. About 10\% (12) said they had sexual relations with all their partners. They did this so as not to jeopardise their relationship because as they claimed, it was not very easy to have male friends with whom one did not have sexual relations. However, during discussions on the strategies employed to reduce the risk of HIV/AIDS by avoiding sex, it became clear that a lot more of the previously proclaimed platonic relationships sometimes involved sex. As one female student put it, 'you must have sexual relations with men in order to make money' (25 years old).

However, not all females perceived sex as an act one engaged in for financial reasons. Other reasons presented for having sex ranged from biological to just fun. For females who presented the former stand point, they believed that after a certain age it became imperative for one to commence sexual relations to satisfy a physical need. Once this started, it then became difficult to stop or abstain. For the third category one had sex for the fun of it.

Subsequently, girls went on to narrate a series of strategies they employed to avoid and or minimize sexual relations with their other partners. The first set of strategies identified by $54.37 \%$ (87) of girls included inventing and feigning illnesses and giving excuses: having a menstrual 
period, heavy academic course load, assignments and abrupt emergency travel plans. A second set of strategies was mentioned by $36.25 \%$ (58) of females who were of the opinion that one could be forthright and honest with their male partners and simply tell them they preferred to abstain from sexual relations and then stick to their decision. This category of females stated they restricted visits by male friends to their rooms. Instead they preferred to pay visits to such male friends in the company of their female friends to minimise pressures from their boyfriends for sexual contact. The last strategy was used by $9.4 \%$ of female students (15) who were more religious inclined and felt that boyfriends should be directed towards religious/moral codes as regards male-female relationship with focus on friendship rather than sex. For them, sex ought to be presented to their male friends as being appropriate only within the context of marriage and family life.

\section{Gender Differences and Perception of Risk of HIV/AIDS among Students}

A higher number of female students $(63.75 \%$ or 102$)$ felt they were at more risk of having HIV/AIDS than their male counterparts. This they said was because the current economic crisis made females vulnerable. It predisposed them to engage in sexual relations with men without the ability or power to insist on condom usage. This was particularly so in relationships with sponsors. Within such context of a financially construed relationship, females were powerless, as it was the men that dictated things. This was also the same for females who felt obliged to engaged in extra-academic relations with male lecturers to enable them graduate on time. Females were also more exposed to being infected due to aesthetic procedures as well as medical and biological factors. Firstly, through the more frequent use of beauty saloons and hospitals, females were made more vulnerable to HIV/AIDS infection. In the former the instruments used in the processes of beautification were not systematically sterilised. In the latter, during child birth and gynaecological examinations e.g. vaginal, cervical tests and curettage one was never quite sure of the equipments or materials used as they were not usually the disposable or unique usage type. Therefore, there were always doubts as to the appropriate sterilisation of equipments and materials before subsequent use on clients. Secondly, it was believed that the female sexual organ in itself predisposed women to HIV/AIDS infections because of its structure, position and humidity. It was said to be warm and hidden in the body like a cupboard which stores and conserves everything put in it. As such, it was prone to culture and nurture microbes.

\section{HIV/AIDS: Families and Students}

Nearly three-quarters of all students $(72.5 \%$ or 232$)$ said they knew persons who were living with HIV/AIDS. Of these, (37.5\%) 87 were living ordinary 'normal' lives, while (62.5\%) 145 were stigmatised. In all, about one-third of students felt since AIDS already deprived its victims of the possibility of 
realising their future plans and dreams, the least they could do was to be kind, warm and sympathetic to them. This would prevent them from feeling isolated, abandoned or stigmatised. They felt those who led normal lives did so because they had not yet started manifesting signs of the illness or they were psychologically strong, having come to terms with the reality of their situation. More important, this category of PLWHAS was able to do so because they had good social support from their families. Their families gave them social and emotional support and also remained affectionate towards them. Stigmatised PLWHAS according to students were essentially those whose friends and family perceived HIV/AIDS as a shameful illness because victims were regarded as sexually frivolous and promiscuous. Feelings of isolation and reject by others were common among those who felt stigmatised irrespective of whether this was enacted or not.

\section{Discussion}

Over the past decade or so, the attitudes of students towards the existence of HIV/AIDS in Cameroon have changed considerably. The belief in the existence of HIV/AIDS is now universal (AIDSCAP 1997; Rwenge, 2000). The disease through the death of a known relative or friend has directly or indirectly affected almost everyone. Knowledge of the modes of transmission of AIDS is also high, as indicated by $95 \%$ of students. About $80 \%$ were also able to identify some prevention strategies. What still remains largely problematic is the failure to translate the knowledge of preventive strategies into protective action and behaviour as other studies have also pointed out (Trebucq, 1988; Tchuppo et al., 1990; Tchuppo et al., 1993).

According to the AIDSCAP results, $70 \%$ of students still indulge in risky sexual behaviour and have multiple partners with whom the use of condom is at best irregular. However, there was a slightly higher increase of condom use among females (36\%) than males (24\%). The official AIDS prevalence rate in Cameroon is between $5-12 \%$. Nonetheless, unofficial estimates are as high as between $17 \%$ to $21 \%$. About three-quarters of the people affected are in the 15-35 years age group. University students clearly fall within this age range. Youths are especially at risk firstly, because they are adventurous and very sexually active, being at an age where sexual hits and conquests are perceived as important for self-esteem. Secondly, they have multiple sexual partners, and are more likely to practice 'innovative' sexual and risky techniques. Thirdly, students are usually financially insecure. Therefore, financial incentives from (older) men exert a strong influence towards their acceptance of risky sexual behaviour, especially as regards non-use of condoms as other studies have also indicated (Silberschmidt and Rasch, 2001; Luke, 2003). The practice of having multiple sexual partners as a form of social security was also found among adolescents in South Africa, (Kaufman and Stavrou, 2002; Varga, 2003) as well as that of stalling others.

Given the prevalence of HIV/AIDS and its growing incidence particularly in Douala, some students are faced with the realities of the 
disease at the domestic level. Sketchy reports from some faculties indicate that some students are discontinuing their education due to death of parents and inadequacy in meeting up with the financial demands of university education. Due to the ravages of HIV/AIDS, dysfunctional parents or guardians are unable to provide adequate care and other duties to students. This translates into loss of financial and social support, particularly at the onset of their academic career. Students also experience psychological trauma from parents who are no longer able to act as such. Also problematic is the morbid fear of their friends and neighbours finding out that their parents or siblings are living with HIV/AIDS or are dying from the virus. The consequences to students include prolonged period of absence from lectures, inability to continue their education due to lack of financial support, the diversion of study time to provide care to sick family members, the obligation to prematurely assume the role of breadwinner, caregiver etc. Some of these students return after one or more years of absence with the intention to re-register. However, few actually succeed in returning to their studies and the majority of them do not return at all. Thus, there is a growing number of students who are unable to complete their education and therefore less likely to have access to future employment, thereby increasing vulnerability to exploitation and abuse especially for female students.

At the other end of the spectrum is the need for parents to transmit appropriate patterns of sexual behaviour to young people. They have important roles to play in determining the sexual behaviour of their children as well as in HIV/AIDS prevention strategies as indicated by several studies. Orphans and youths from dysfunctional families are more likely to commence sexual activity earlier than those from stable families and also they engage in risky sexual behaviours (Caldwell, 1993, Naré et al., 1997). Grandparents could also contribute towards inculcating positive normative patterns of sexual behaviour to youths. However, parents are often unwilling and or unable to participate in the sexual education of their children. Due to several factors grandparents are increasingly unlikely to reside within the same households as their grandchildren as in the past especially in urban areas (Ilinimugabo et al., 1996; Madzouka, 1991; Njikam Savage, 1998).

There are gender differences as regards self-perceived risks of HIV/AIDS infection between females and males as Watkins (2004) found in Malawi. However, it is not clear if this translates to protective behaviour. Studies by Duncan et al. (1997); Douglas et al. (1997); and Paolisso and Leslie, 1995 indicated gender differences in rates of STIs and HIV/AIDS infections. Like in other STIs, females have a higher risk of being infected by HIV/AIDS than males because of their different physiological make up as well as the interplay of a host of social, cultural and economic factors (UN, 2001). These include dysfunctional families, low female status which down-play the intrinsic value of the girl-child and woman and reduces it to just their sexual and reproductive roles as potential wives, child-bearers and rearers. In 
addition, double sexual standards for males and females encourage girls and women to perceive and use sex as a commodity. Socio-cultural practices such as body-piercing, body-scarification, female genital mutilation, early child marriage, dry sex with the risk of vaginal trauma and polygyny (Orubuloye et al, 1993) continue to put young girls and women at risk. Also, widowhood rites, widowhood inheritance and the ritual cleansing and washing of the dead (Douglas et al. 1997; Ngwane, 2001), which further put women of all ages at more risk of being infected by HIV/AIDS. Consequently, females are more likely to be infected by the HIV than their male counterparts.

Furthermore, some students work as part-time prostitutes in certain vicinities in town especially during weekends and vacations to augment their allowances. Within the context of commercial sex, unprotected sex attracts a higher fee from clients. Given the level of sexual activity among both male and female students and the extent of their sexual networking, they constitute a high-risk category in the HIV/AIDS scenario. Most students have strong family links with the rural areas and therefore are involved in 'home' visits especially during the long vacations and festive seasons. This further increases the scope of sexual networking (from urbanrural-urban) and the possibility of transmitting the virus or being infected.

Although there were several negative attributions to the use of male condoms, students appeared to be ignorant of the female condom. Students of either sex did not make allusion to its existence or use. This may be an indication of ignorance or non-perception of the female condom as a possible option for females and males towards the prevention of unwanted pregnancies, STIs and HIV/AIDS. The female condom has low publicity and almost zero visibility. It is hardly discussed on the radio or seen in the print media or television. Although it is being sold at subsidised rates in some health facilities at $\$ 0.65$, most pharmacies sell it for about $\$ 1.4$ nearly four times higher than the cost of a male condom which can be purchased for as low as $\$ 0.33$. Some critiques have raised certain negative attributes concerning the usage of female condoms: it is noisy, large and hangs out. Non-allusion may be indicative of ignorance, non-acceptance and or non-use of the female condom. This is somewhat surprising especially among young university undergraduates who are usually quick to catch up with innovations.

Due to the location of the university in the economic capital, the students of the University of Douala have a series of available health facilities (both government and private) especially within the context of HIV/AIDS sensitization and prevention programmes. In 2001, concerned by the alarming increase in HIV/AIDS prevalence in Cameroon and the implications for the youths in higher educational institutions, the Ministry of Higher Education in collaboration with the World Bank, the Ministry of Public Health and the National AIDS Control Committee (NACC) and some non-governmental organisations (NGOs) drew up a Plan of Action for 
HIV/AIDS. Since 1999, CAMNAFAW has been running a Health Programme within which a Youth Clinic operates and offers fertility control facilities among other facilities for youths. Youths are still reticent about using regular government hospitals and health centres for matters pertaining to reproductive health and fertility control. This is because most youths perceive such health facilities as being run and used by adults and therefore socio-culturally inappropriate for them (Tchetgnia, 2001). Although, the University of Douala supports several Youth health programmes in a bid to promote the reproductive health of students, it is within the past two years that it has increased its activities in the sphere of HIV/AIDS sensitization and prevention. In response to growing HIV/AIDS prevalence among youths and specifically among University of Douala students, a special service, the Listening and Counselling Service was set up by the University Health Centre within its Social Welfare service to provide confidential services to those in need. The University Health centre currently has two physicians, one social worker and five nurses. It also has some laboratory facilities where medical laboratory tests are conducted. In an effort to address the health needs of its students part of the proposed plan of the University include, the intensification of I.E.C. on prevention strategies, the setting up of HIV/AIDS screening facilities on Campus with an integrated pre-and post counselling programmes, the introduction of a pilot treatment and management scheme for those infected as well as the expansion of existing social welfare programme.

Other prevention strategies that could be employed include empowering young adults to practice sexual abstinence and fidelity through the development and teaching of life skills, identifying and valorising positive cultural norms and the training of peer leaders. Although, there is a tendency to overlook abstinence as unacceptable, impracticable and old fashioned, results from studies conducted among 130 young male adults in Douala, with a mean age of 17.69 , years revealed that although $70(53.85 \%)$ were sexually active, $60(46.15 \%)$ declared themselves to be virgin and expressed the desire to remain so until marriage. They opted for pre-marital chastity primarily to avoid unwanted pregnancies (Njikam Savage, 2001). Results from this study also indicated the importance of religion on a small but present number of students who supported the practice of premarital chastity. Preliminary investigations from a pilot project on Health Promotion among University of Douala students similarly revealed some individuals who stated that they were virgins and were determined to remain so until marriage were involved in religious activities.

\section{Conclusion}

The above results have direct implications for both government and nongovernmental bodies such as educational, health, social and religious agencies who are involved in reducing the spread of HIV/AIDS infections among youths as well fostering the concept of responsible youth. 
The age of enrolment into university programmes is increasingly declining and can sometimes be as low as 16 years. Such students are expected to have metamorphosed literally overnight into adults with the ability to make informed decisions on sex and sexuality, issues which are largely undiscussed in schools and homes. As students spend a considerable amount of time away from home on campus, for many of them, the University arena constitutes a niche for exploratory behaviour some of which are by nature sexual. The University therefore, constitutes a priority place for promoting and enhancing healthy sexual behaviour among students especially in the face of growing HIV/AIDS prevalence. Thus, there is an urgent need for a systematic review of methods to reduce high-risk sexual behaviour among them. To start with, well-designed and exploratory studies are essential to provide meaningful results. This would then form a basis for appropriate intervention strategies, including health education programmes, especially as concerns prevention, health enhancing, treatment and management protocols for this important and growing segment of the population. In addition, appropriately designed I.E.C. materials for youths could be developed to address some of the above issues.

\section{References}

AIDS Control Programme (AIDSCAP). 1997. Connaissances, Attitudes, Croyances et Practiques.

Caldwell, J. C. et al., 1993. African Families and AIDS: Context, Reactions and Potential Interventions. Health Transition Review. Supplement: 1-6.

Douglas, A., O'Hara, P. et al., 1997. HIV Prevention among Zambian Adolescents ; Developing A Value Utilisation/ Norm Change Model. Social Science and Medicine. 4 (44): 455-468.

Duncan, M., Tibaux, G. et al., 1997. STDs in Women Attending Family Planning Clinics : A Case Study in Addis Ababa. Social Science and Medicine, 4 (44) : 441454.

Ilinimugabo, A., Walla, G. et al., 1996. Causes et conséquences des grossesses chez les adolescents au Cameroun. Research Report Series 3, Yaoundé, Cameroun: Center for African Family Studies and Cameroon National Association For family Welfare.

Jaramillo, E. 1999. Encompassing Treatment with Prevention: the Path for a Lasting Control of Tuberculosis. Social Science and Medicine, 49 (3): 393-404.

Kaufman, C.E. and Stavrou, S. E. 2002. "'Bus Fare Please': The Economics of Sex and Gifts among Adolescents in Urban South Africa." Research Division Working Paper No.166. New York: The Population Council.

Khan, A. et al., 2002. Tuberculosis in Pakistan: Socio-cultural Constraints and Opportunities in Treatment. Social Science and Medicine, 50 ( 2): (247-254).

Kuaban, C. and Bercion, R. 1996. Séroprévalence de l'infection à VIH chez les adultes atteints de tuberculose pulmonaire bacillifère à Yaounde-Cameroun. Médicine Tropicale, 56 ( 4) : 357-359.

Luke, N. 2003. Age and Economic Asymmetries in the Sexual Relationships of Adolescent Girls in Sub-Saharan Africa. Studies in Family Planning, 34 (2): 67-86.

Madzouka, J. 1991. La Transmission des normes aux jeunes : quels modes préférentiels? in Union for African Population Studies (UAPS), Dakar, Sénégal. Femmes, Famille et Population, 1: 193-204. 
Meeting of Experts on Identification of Areas of HIV/AIDS Transmission in Douala. July 31 2003 , Douala.

Naré, C., Katz, K and Tolley, E. 1997. Adolescents' Access to Reproductive Health and Family Planning Services in Dakar (Senegal) African Journal of Reproductive Health , 1 (2): 15-23.

Ngwane, S. 2001. Women and AIDS in Cameroon: Prevention and Management Strategies. Paper Presented at the Catholic Women's Association Divisional Conference, Douala, Cameroon.

Njikam Savage, O.M. 1993. Family and AIDS. Paper Presented at a Round Table Conference on AIDS, University of Douala.

Njikam Savage, O.M. 1998. Adolescents' Beliefs and Perceptions towards Sexuality in Urban Cameroon. pp. 77-90. In Sexuality and Reproductive Health during Adolescence in Africa with Special Reference to Cameroon. ed. B. Kuate-Defo. University of Ottawa .

Njikam Savage, O. M. 2001. Changing Perspectives on Sexuality, Family and Marriage among Young Male Adults in Doauala, Cameroon. Presented at the Pan African Anthropologist (PAA) Conference, Libreville, Gabon.

Orubuloye, I., Caldwell, J. et. al., 1993. African Women's Control over their Sexuality in an Era of AIDS. A Study of the Yoruba of Nigeria. Social Science and Medicine, 37 (7): 859-872.

Paolisso, M. and Leslie, J. 1995. Meeting the Challenges of Women in Developing Countries. Social Science and Medicine, 1 (40) :55-65.

Rwenge, M. 2000. Sexual Risk Behaviors among Young People in Bamenda, Cameroon. International Family Planning Perspectives, 26 (3):118-123, 130.

Silberschmidt, M. and V. Rasch. 2001. “Adolescents Girls, Illegal Abortion and 'Sugar Daddies' in Dar es Salaam: Vulnerable Victim and Active Social Agents." Social Science and Medicine 52 (12): 1815-1826.

Tchetgnia, L. F. H. 2001. Aspects sociologiques des déterminants et problèmes de la sous utilisation des Services de planification familiale par les adolescents à Douala. Mémoire de Maîtrise en Sociologie et Anthropologie de la Santé.

Tchuppo, J. P. et al., 1990. Résistance au changement des conduites sexuelles face au SIDA : une étude psychologique des obstacles à l'utilisation des préservatifs (le cas des étudiants de l'Université de Yaoundé 1, Study Report, Yaoundé, Cameroon.

Tchuppo, J. P. et al., 1993. Les Etudiants des universités de Douala et Yaoundé face au SIDA et MST. Données qualitatives sur les connaissances, attitudes et pratiques, Yaoundé, Cameroon: AIDS-CAP/Population Services International.

Trebucq, A. 1988. Adolescence, comportement sexuel et risque d'infection à VIH à Yaoundé, Cameroon: Organisation pour la Lutte contre les Endémies en Afrique Centrale (OCEAC).

UN. 2001. United Nations Declaration of Commitments on HIV/ AIDS. Documents, Population and Development Review, 27 (3): 619-624.

Varga, C. 2003. How Gender Roles Influence Sexual and Reproductive Health among South African Adolescents. Studies in Family Planning, 34 (3):160-172.

Watkins, S. C. 2004. Navigating the AIDS Epidemic in Rural Malawi. Population and Development Review, 30 (4):673-705.

\section{Footnotes}

1. Sponsors refer to older men, also known in the literature as sugar daddy, who keep younger girls and satisfy their financial needs. In return the girls are available on demand for social outings and sex. 